\title{
Cultural Sustainability and Heritage Tourism: Problems in Developing Bun Festival Tourism in Hong Kong
}

\author{
Matthew M. Chew \\ Department of Sociology, Hong Kong Baptist University \\ Kowloon Tong, Kowloon, Hong Kong SAR, China \\ Tel: 85-2-3411-7132Ｅ-mail: mmtchew@hkbu.edu.hk
}

\begin{abstract}
This study contributes to the debate on tourism and local development through evaluating an ambivalent case of traditional festival revival and tourism development in Hong Kong: Bun Festival tourism in Cheung Chau Island. The significance of this case is that it will put into relief the significance of 'cultural sustainability' — an evaluative factor that is very insufficiently emphasized and theorized in current critical studies of tourism development. I will show although the most often mobilized critiques against heritage tourism development — including cultural inauthenticity, commercialization, lack of local economic development, and local disempowerment - can be applied to the case of the Bun Festival tourism, particular social circumstances weaken the force of these critiques in the Hong Kong case. Many local residents of the Cheung Chau Island approve the neoliberal direction of current tourist development and derive economic benefits from it. Even critical commentators in Hong Kong are not entirely against it. This study will point to evidence and arguments that uncover a serious and neglected problem in Bun Festival tourism: that neoliberal exploitation of heritage tourism resources threatens the cultural sustainability of historically rooted local practices of the Bun Festival and in turn threatens the viability of Bun Festival tourism in the long run.
\end{abstract}

Keywords: Festival tourism, Heritage tourism, Tourism development, Cultural authenticity, Cultural commodification, Cultural sustainability, Bun Festival

\section{Introduction}

The relationship between tourism and local development is one of the most debated issues in tourism studies. Some implicitly assume that when tourism generates wealth, that wealth will gradually promote development of local places and trickle down to local residents. Critical scholars of tourism, however, doubt that tourism development, especially in its current neoliberal forms, can bring about genuine and sustainable development for localities. Through numerous case studies and analyses of empirical data, they have shown that tourism often hurt localities in economic, environmental, socio-political, and cultural ways, and that the only real benefactors are often the national state and global capital (eg. Harrison, 2001).

This study contributes to the ongoing debate on tourism and local development through evaluating an ambivalent case of tourism development based on a traditional festival revival in Hong Kong: Bun Festival tourism in Cheung Chau Island of Hong Kong (Note 1). The significance of this case is that it will put into relief the significance of 'cultural sustainability' - an evaluative factor that is very insufficiently emphasized and theorized in current critical studies of tourism development (Throsby, 2007). I will illustrate that although the most often mobilized critiques against heritage tourism development - including cultural inauthenticity, commercialization, lack of local economic development, and local disempowerment - are applicable to the case of Bun Festival tourism, particular social circumstances weaken their force in the Hong Kong case. Many local residents of the Cheung Chau Island approve the neoliberal direction of tourist development and derive substantial economic benefits from it. Even critical commentators in Hong Kong are not entirely against it. This study will reveal a serious and neglected problem in Bun Festival tourism: that neoliberal exploitation of heritage tourism resources threatens the cultural sustainability of historically rooted local practices of the Bun Festival and in turn threatens the viability of Bun Festival tourism in the long run.

\section{Social historical context of Bun Festival's revival}

Since there are not yet any English language studies of the Bun Festival, I provide here a brief historical context of it as a background for analysis in the substantive parts of this essay. What is currently called in the English language as the 'Bun Festival' is the 'Taiping Qingjiao' (sacrificial ceremony of peace and purity) ceremony organized by the local residents of Cheung Chau Island in Hong Kong (Choi 2002; Choi 2007). There are similar 'Dajiao' (Daoist sacrificial 
ceremony) festivals in other parts of Southern China and Taiwan, but that of Cheung Chau is currently one of the most well-known one because it features exotic and spectacular elements such as the Bun Scramble event. The mythic origins of Bun Festival of Cheung Chau Island was that it started over 200 years ago when the gods helped local people to survive either a plague or a group of vicious pirates. The Bun Festival currently takes place in early May each year and lasts for five consecutive days. A long list of activities take place in the five days. Aside from the two biggest tourist attractions - the Bun Scramble and the Floating Children Parade - there are also other parades, street cleansing, burning of paper effigies, lion and dragon dances, vegetarian meals, Cantonese opera, and other activities that tourists can watch.

The term 'Bun Festival' was inspired by the steamed buns used in the Bun Scramble event. The Bun Scramble features competitors (who used to be exclusively local residents of Cheung Chau Island) racing upward along 60-feet bamboo tower covered with thousands of steamed buns in order to snatch the bun on the very top of the tower. In 1978, more than 100 people were injured when one of the bun towers collapsed during the race. The government banned the Bun Scramble event after that incident. In the late 1990s, the Island's local tourist revenue dwindled sharply under a confluence of factors including the Asian Financial Crisis and the Island's turning into a notorious suicide spot for Hong Kongers. In 2003, Taiping Qingjiao happened to become the first local festival to occur immediately after the SARS epidemic subsided in Hong Kong. It gained great success as citizens visited the Festival to relax after experiencing the threat of the lethal epidemic for months. Because of the Festival's success in 2003, local leaders of Cheung Chau Island negotiated with the government to revive the Bun Scramble event. The Hong Kong government, which completely embraces neoliberal discourses regarding tourism development, promptly accepted the proposal and subsequently tried to construct the Festival into one of Hong Kong's cultural tourist attractions. In 2005, the Bun Scramble was revived and the tourism discourses on Hong Kong started to market it as the centerpiece of the Festival (Chiu and Tang, 2005). The Festival has been attracting between 40,000 to 50,000 of domestic and international tourist visits to the Cheung Chau Island each year since 2004 (Hui, 2004).

\section{Cultural authenticity}

Cultural and heritage tourism in developing localities tends to be plagued by the problem of inauthenticity. In the commercialized marketing of a local place, its cultural tradition, artifacts, architecture, people, and commodities, the imperative of cultural authenticity often is de-emphasized for the purposes of expedience and cost-effectiveness. Additionally, inauthentic cultural products are manufactured in order to attract the largest number of tourists to consume a locality's culture. This inauthenticity can undermine a locality's heritage directly and indirectly; it displaces the authentic heritage tradition, misinforms tourists, and trivializes cultural differences.

Similar to other cases of heritage tourism, Bun Festival tourism reproduces numerous components of its heritage in distorted and inauthentic ways. A controversial example of its inauthentic cultural reproduction involves the buns used in the Bun Scramble. In the past, edible steamed buns made of flour were stacked on bamboo poles to constitute bun towers. Since 2007, the government and local elites agreed to use plastic buns instead of real, edible ones. The plastic bun, which was subsequently named 'pingan bao' (bun of peace), came to be successfully promoted as the talisman and trademark image of the Bun Festival. The plastic buns used on the bun towers were given as souvenirs to tourists. And a wide range of souvenirs themed with image of bun of peace are designed, manufactured, and sold to tourists. There was a small scale public debate in Hong Kong surrounding the adoption of plastic buns (Choi, 2007; Fung, 2007; Kwan, 2008; Lee, 2007). Critical commentators especially point to the irony and sacrilege in the elevating of a recently invented artifact (the plastic bun) into the trademark of the traditional festival.

Another example of cultural inauthenticity is the sanitization and sportification of the Bun Scramble event. Although less discussed by the public than the issue of plastic buns, this example is no less illustrative. The Bun Scramble, at least during its past few decades of existence, performed a social function beyond its religious ritual role. It constituted an arena of competition among different major clans and secret society groups on Cheung Chau Island. These different groups showed off their bodily strength, which in turn correlates to social power in the semi-underworld environment of the Island. The scramble for the top bun was a test of the muscle power of each group and a struggle for social power among the groups (Choi, 2001; Leung, 2007). This social function of the Bun Scramble is not particular conducive to promoting tourism, however. Moreover, its partial connections to organized crime and underground societies could tarnish the civilized image of Hong Kong and the administrative authority of the Hong Kong government. That is why the Bun Scramble has been increasingly reconceived and re-organized as a sports event after its revival in 2005. Participation of the Scramble is widened to the Hong Kong public and international community of sport lovers. The event is reported and televised in the news. Strict safety standards are implemented in the building of towers. For example, a steel structure substituted the traditional bamboo structure since 2005. The Bun Scramble is being marketed to the international public as a unique, ethnic kind of rock climbing sport. The event is thoroughly sanitized: with global participants and international tourist spectatorship, it can no longer function as a competitive arena among clan factions and local secret societies. 
The expedient transformation of steamed buns into plastic buns and the sportification of the Bun Scramble are doubtlessly a manifestation of the general problem of cultural inauthenticity observable in tourism development across the globe. They are different, however, from the worst cases of cultural inauthenticity in that there are tenable arguments that justify them. The use of plastic buns is more environmental friendly, hygienic, and economical (to the local community) than real, edible ones. Using a great deal of food for props is wasteful. Very few participants and tourists would want to eat the buns after the Scramble. This is not simply because steamed buns without fillings are unremarkable staple food that is seldom eaten in contemporary Hong Kong. The buns used in the event have to be made in advance and hence are a few days old when the Bun Scramble activities conclude. Moreover, in rainy and humid weather, the buns can go moldy, decompose, and fall off the bun tower. It happened once and the local festival committee had to spend extra money to purchase new buns to replace them. As the Festival and the Bun Scramble event grew, the number of buns required and the money needed to purchase them also increased. It has already reached a point where getting sufficient funding to purchase buns for the bun towers became a heavy burden on the local festival committee. Government funding for the Bun Festival remain very limited — the amount (100,000 Hong Kong dollars; USD $1=$ HKD 7.8) is not even enough for purchasing steamed buns for the three bun towers. Plastic buns provide a solution to many of the problems that edible buns cause. Plastic buns are immune to weather changes. They cost two times more than edible buns but because they can be reused for several years at least, they are more affordable in the long run. That is why many local residents, local businesses, and local festival organizers gladly joined hands with the government to make the switch to plastic buns despite its deviation from traditional practices (Chan, 2007).

The sportification and sanitization of the Bun Scramble was in practice motivated by neoliberal and governance imperatives more than anything else (Sofield and Sivan, 2003). However, there are three reasons that compel local people and critics to tolerate if not support the transformation. The first reason to tolerate the present form of sportification and sanitization is its abandonment of the social exclusionary structure of the previous form. Women were informally excluded from the event. Outsiders, including Hong Kong citizens who were not from the Cheung Chau Island and foreign visitors, were also excluded. Since 2005, the Bun Scramble event has become formally opened to both groups (Editorial, 2005).

The second reason to tolerate sportification and sanitization is that the social competitive function of the original event has already become less meaningful to natives of the Island in the contemporary period. The Island was much more socio-political isolated from Hong Kong a few decades ago than now. Dominant local clans and underground societies indeed enjoy a great deal of socio-political control over the Island's residents. But historical social factors have already undermined the control of clans and underground societies over the Island. They include globalization, advanced communicative technologies, demographic changes of the Island (a small influx of new non-local residents and out-migration of young natives), a post-Handover government that is less tolerant of alternative socio-political organizations, and local business efforts to develop the Island into a domestic tourist spot in the past two decades. The contemporary socio-political landscape of the Island renders the local competitive function of the event obsolete and anachronistic. It is likely that even without government imperative and policy intervention, the event would be still be transformed in a direction that is similar to present changes as its original local socio-political function fades.

The third reason to tolerate sportification and sanitization involves the personal safety of participants of the Bun Scramble event. When the event functioned primarily as an arena of local factional competition in the past, injury of participants was not a problem to any parties. Because the Scramble was supposed to be a display of bodily power, masculinity, and kung-fu expertise of the participants, it was against participants' own interest to complain about injuries incurred in the event. It also made no sense to sue the organizers if someone was hurt because most participants were connected to the organizing committee. When the Scramble is opened up to participants other than local residents, liabilities increased and safety precautions had to become stricter. The local community has become the host rather than the sole consumer of the Scramble event. Injured outsider participants - who did not join the event to war against any local factions - have no reason to withhold criticism or lawsuits against the event if their injury was caused by the organizers' neglect.

\section{Commercialization, commodification, and their local economic impacts}

Local tourism development in the contemporary world always involves commercialization and commodification; neoliberal directions of local tourism development that the Hong Kong government pursues encourage rampant commercialization and commodification. Local cultural heritage, services, local spaces, community relations, and anything that can be made to create economic profit become targets of commercialization. In the few years after the Bun Festival was targeted as a focus of tourism development, commercialization has already become very salient and commodifying processes are already powerfully re-shaping the contents of the Festival. I will analyze an example of these processes and then assess local economic impacts of commercialization and commodification.

Apart from the spectacular Bun Scramble event, the most widely reported aspect of the Bun Festival in the domestic news of Hong Kong is it souvenir products. Numerous souvenir products have been designed to take advantage of Bun 
Festival tourism since 2005. They include cushions, wallets, tee shirts, fans, edible bun gift sets, key holders, mobile phone accessories, and other gadgets themed in the form of the Bun, the talisman of the Festival (Chan, 2008). Some of the products, such as 'Bun-Man' dolls and electronic game pens, are innovative in terms of design but glaringly irrelevant to the Festival. But disneyization of the Bun Festival cannot do without the production and consumption of such themed and merchandized goods though (Bryman, 2004). Similar to Disneyland, Cheung Chou Island during the Bun Festival offer themed events, themed goods, and themed food. To the majority of domestic tourists, shopping for such products constitutes the only concrete experience of participating in - instead of being a simple spectator of the Bun Festival.

The fact that innovative, lucrative, and themed souvenir products are generated for a local tourist spot is nothing new or unusual. Similar processes can be observed elsewhere in the world. But the speed with which this process took shape and became established in the case of the Bun Festival is noteworthy. In only three years of time, a large product range is produced and well known brandnames were established on the basis of these goods. The production of these souvenirs is organized by small businessmen, some of whom are natives of the Island. In popular media discourses, emergence of these products are portrayed entirely in neoliberal narratives — small entrepreneurs successfully harnessing creativity and innovative instincts to generate wealth. The earliest and most commercially successful entrant to this market was Studio 8.5 and it is praised in these terms (Wu, 2007). One of Studio 8.5's three owners is a native of Cheung Chau who resided in the Island until he was 19 years old (Anon, 2007a). The company built up its brand by selling cushions and other well-designed souvenirs products in 2006. By 2009, it is selling a larger range of souvenirs, steamed buns, and specialized Cheung Chou food products including shrimp paste. Another successful brandname, 'Mr Bun,' is founded by a native born artist who sells tee shirts.

The distribution of souvenirs relied on retail shops and flea market stalls opened in the duration of the Festival. Many of the souvenir products are retailed through consignment terms - Hong Kong producers supplying the products and the Island's local retailers providing retail space and service. Powerful players such as Studio 8.5 set up their own flea market stalls to sell their products, however. Most local retail shops and restaurants are run by locals but most flea market stalls are not.

The previous example illustrates that commercialization is progressing at a fast pace in Bun Festival tourism. Commercialization can hurt cultural authenticity. The inundation of tourists' festival experience with bun-themed souvenirs and non-traditional food products clearly undermine cultural authenticity. But because cultural authenticity is different to measure and critique of cultural inauthenticity has its own theoretical problems, critics of commercialization often focus on another important problem brought about by commercialization: whether commercialization is achieving its major positive mission in tourism development - the support of the local economy and enrichment of local residents. In the Bun Festival case as well as others, a central factor to answering this question is whether the profits resulted from commercialization flow largely to corporations outside the locality or to local entrepreneurs and residents.

Currently, most of the retail shops, motels, and restaurants are locally owned. Many motels witness full house or substantial occupancy increases during the period of the Festival (Ng, 2008; Hao, 2009). Additionally, hotel operators outside of the Island cannot easily encroach on this market. Restaurants and food shops greatly benefited from the 50,000-strong tourist traffic. The leading local bakery, Kwok Kam Kee Cake Shop, sell approximately 70,000 buns and gained 420,000 Hong Kong dollars (USD $1=$ HKD 7.8) of revenue during the Festival period. Kwok, the owner, thinks that competition from the outside does not pose a challenge to his business (Anon., 2008a). Food businesses from outside the Island are devising different plans to encroach on the Bun Festival food market and share the profits. But they have to compromise with local business elites in order to achieve this. For example, Studio 8.5 (partly owned by a Cheung Chau native) has to made deals with local businesses and back off from the bun market. Instead it will focus on non-traditional foods and promote specialized dried foods produced by local residents (Anon, 2008b). The McDonald's restaurant on the Island also sells vegetarian food in order to theme itself, attract tourist consumption, and pay respect to local practices.

The making and retailing of souvenir goods is the area which businesses from outside the Island can encroach on the market without much local elite interference. A significant part of the merchandize has to be distributed to tourists through local retail shops in the Festival duration. But non-local business can also set up independent flea market stalls - which are permitted and organized by the Hong Kong government — to sell their ware (Anon., 2007b). Studio 8.5 is said to have made over HKD 100,000 of profits this way in 2007's Festival duration (Fat, 2008). Studio 8.5 is also selling Bun Festival souvenirs and themed food products from the Island in retail outlets across Hong Kong (ie. outside of Cheung Chou Island) all year long. By doing this, it on the one hand drains revenues from the Island's tourist business and on the other hand helps to market the Island's produce and the Island to a broader consumer base. Although businesses from outside Cheung Chau Island are sharing the profits generated by the Festival, they have not been able to suppress local businesses and are not likely to be able to do so in the near future. Local entrepreneurs from the Island are as knowledgeable as others Hong Konger about running small business. Moreover, they are well 
positioned geographically and politically to capture the economic profits generated by the Festival.

Total expenses required by the Festival amounted to approximately HKD 1,300,000 each year in the past few years (Chan, 2008). Government subsidy was around HKD 100,000 per year. Local residents, businesses, and elites had to spend HKD 1,200,000 each year to cover the difference; gifts from commercial sponsors amounted to around HKD 200,000 in 2008 (Kwan, 2008). This means local businesses have to make at least a million HKD in profits in order to turn the Festival into an independently profitable event. While no detailed and reliable statistics of profit figures of local business are available, the Festival is likely to be independently profitable to locals. Kwok Kam Kee alone is booking over HKD 200,000 of profits and the tiny operation of Mr Bun made the local artist around HKD 50,000 (Anon, 2007b). 4,000 electronic game pens were sold in 2007, making the local businessman approximately HKD 40,000 in profits (Yeung and Chik, 2008). Each medium sized local restaurant can earn around HKD 6-70,000 of revenue per day in the peak days of the Festival (Yeung and Chik, 2008). Added to these the profits of local motel operators and restaurants, the total profits of the Festival duration are likely to exceed a million Hong Kong dollars.

\section{Local disempowerment or empowerment?}

From the perspective of local residents affected by festival and heritage tourism, cultural authenticity and commercialization may not be the most relevant or urgent problematic (Hampton, 2005). Instead, they may care more about whether tourism development is empowering or disempowering them (Cole, 2007). However, because empowerment involves multiple dimensions including the economic, the social, the political, and the self, it is not often easy to measure the local empowerment impact of tourism development. The case of Bun Festival tourism illustrates this complexity.

Viewed from a political angle, the local residents of Cheung Chau Island were not particularly empowered by Bun Festival's revival and tourism. They may actually have been disempowered by it. In the course of government orchestration of the Festival's revival and subsequent development, the reach of the state is concretely extended. Decisions regarding details of the Bun Festival used to be relatively autonomously decided by the local festival committee, but they can be compromised by government imperatives and considerations in the present. For example, to facilitate and simplify the police's work of keeping order during the Festival duration, historical routes of parades have to change and certain local areas are designated as restricted zones. To minimize the liability of the Floating Children Parade, the government pressured the organizers to spend an exorbitant amount of money on buying insurance for the floating children performers. The sanitization of the Bun Scramble and other aspects of the Festival also reflects the undermining of local self-governance and extension of state power. Of course, the government does not always manage to have its way in its formal and informal negotiations with local residents. For example, when the government wanted to reschedule the Bun Scramble event to the daytime to make it more convenient for governance and more user-friendly to tourists, the local festival committee adamantly refused to deviate from the historical practice of starting the event at midnight. The bureaucrats eventually had to back down. On the whole, however, power being ceded to the state from the local elite seems to be the main trend.

Viewed in social terms, whether there is local empowerment or local disempowerment is also unclear. Social integration and identity forging are two of the major social functions of traditional festivals. The revival of the Bun Festival contributes to achieving these two goals for the local community. The subsequent development of the Festival into a widely participated and news worthy event could have weakened the social integration function to some extent. The presence of too many outsiders, the strong need to put on a good show for tourist-spectators, and rampant commercial activities tend to distract from intra-community social bonding. Yet these new circumstances can also contribute to the identity forging function. Local identities are often strengthened by heightened outsider attention and symbolic boundary construction between locals and outsiders.

Viewed from the economic perspective, however, Bun Festival tourism has unmistakably promoted local empowerment. A significant part of the economic profits of the Bun Festival are reaped by local businessmen, as discussed in the previous section. The economic dimension of local empowerment complicates the overall picture of local empowerment in the Bun Festival case by a great deal. This complexity may be explicated through a stakeholder analysis. The major stakeholders of the Festival include the Hong Kong government, local residents of Cheung Chau Island, citizens of Hong Kong, domestic (Hong Kong) tourists of the Festival, and international tourists. In typical cases of heritage tourism development, each stakeholder has a different set of interests and is differently positioned so that they potentially conflict with each other on a range of issues (Ritchie and Inkari, 2006). We also expect to find such conflicts in Bun Festival tourism. For example, one would expect local residents to disagree with Hong Kong's government and citizens on certain issues regarding the Festival. For example, while local residents traditionally see the Festival as their socio-religious heritage, Hong Kong's government and citizens are gradually seeing the Festival as a profitable cultural property of Hong Kong. One expects antagonism between the host (local residents) and guests (international and domestic tourists) to be present, though it may not be very significant due to the short duration of the Festival. One would also expect casual tourists from Hong Kong to try to shape the Festival in ways that are very different from 
sophisticated cultural tourists from abroad.

Despite potential conflicts among these stakeholders, there exists an important consensus among the most of them. Because of this consensus, potential conflicts are greatly alleviated and many local residents feel personally empowered by festival tourism rather than disempowered by it. The consensus is the prioritization of neoliberal economic development and generation of profits above all else by Hong Kong's bureaucrats, local residents of Cheung Chau Island, citizens of Hong Kong, and domestic tourists. There are probably members of these four overlapping groups who do not prioritize neoliberal development of the Bun Festival over preserving the local heritage of the Festival, but they are a very small minority. Ranked the freest and most business-friendly economy on Earth for the past fifteen consecutive years, Hong Kong is one of the most neoliberal places in the world. Financialization and real estate speculation have since the 1980s been the most common themes in the daily discourses of Hong Kongers and their mass media. Local residents of the Island live under the same discursive environment. They have also been developing their Island into a holiday resort for the young and lower-middle class since the 1980s. While Cheung Chau Island remains a relatively secluded community populated mostly by the native-born, it is also located at 90 -minute's ferry ride from the busiest central business district of Hong Kong.

Only a handful of domestic critics, scholars, and journalists raised objections against the neoliberal revival of the Bun Festival. International cultural tourists, who should be disappointed by excessive neoliberal transformation of heritage, have not yet expressed any negative sentiments because Bun Festival tourism is still new. There are older local residents of the Island who view the commercialization of their festival heritage with ambivalence, but most locals do not. Becky Chan (2008), who is a native of the Island, interviewed many local residents in 2008 and found that the young, the socio-political elite, and businessmen among them largely welcomed recent transformations of the Festival and the consequences of heritage tourism. While they may not approve all changes brought about by neoliberal tourism development, they think that the financial gains from Bun Festival tourism are substantial enough to justify the undesirable socio-political changes. Many also think that the financial gains are helping to maintain heritage activities that were slowing dying anyways. These discourses show that locals of the Island, similar to other Hong Kongers and residents of developing localities, tend to strongly equate economic benefits with personal empowerment (Oviedo-Garcia, Castellanos-Verdugo, and Martin-Ruiz, 2008). Political and social empowerment is not terribly important in their agenda. That is why local residents have been very proactive in partnering with the Hong Kong government to develop the Festival and no local collective action against Bun Festival tourism has been reported.

\section{Cultural sustainability}

Environmental and ecological sustainability does not appear to be a serious problem in the case of Bun Festival tourism. The Festival's duration is sufficiently short. The Festival is certainly economically sustainable as most of the major stakeholders focus on it. Social sustainability could be a problem in certain aspects, as previously discussed in association with social empowerment. However, local residents' local identities are not particularly threatened by Bun Festival tourism. The younger generations and the elite of the Island have long been exposed to urbanized, modernized, and cosmopolitan influences from the global city of Hong Kong.

But cultural sustainability is a real problem. It is being threatened by current ways of developing Bun Festival tourism. There are three ways that a neoliberal direction of tourism development is undermining cultural sustainability in the Bun Festival case. Firstly, sportification, commodification, and commercialization encroach on and eclipse the heritage dimension of Bun Festival tourism. This problem overlaps to s small extent with that of cultural authenticity, except that the focus here is on the loss of historical elements of heritage rather than the loss of authenticity. This is a subtle difference. Because traditions are indeed constructed and ever-evolving, it is problematic to interpret contemporary transformations of Bun Festival heritage as any less authentic than, say, the Festival's form in the 1970s. The 1970s version of the Festival was likely a greatly modified version of the early $20^{\text {th }}$ century version anyhow. It is doubtful, for example, that steamed buns had been used profusely in the early $20^{\text {th }}$ century when Hong Kong was less prosperous or that social competitive functions had been as prominent when the Island was much less populated. However, the cultural sustainability critique of erosion of historical heritage elements in the Festival's contemporary form is not predicated on the critique that contemporary transformations of the Festival are inauthentic.

It is an observable and empirical fact that certain historical elements of the Bun Festival are displaced or replaced by contemporary elements. Examples include the turning of Bun Scramble into a rock-climbing sport, the wearing of contemporary costume by floating children, the broad serving of modern Western foods such as cotton candy, or the proliferation of contemporary bun-themed products such as electronic game pens. One can remain entirely agnostic about the authenticity and normative status of these changes, while pointing to the practical problems they create for Bun Festival tourism in the longer run. The Bun Festival is marketed as a cultural heritage tourism event. If tourists find that its contents contain too few historical elements, they may lose interest in the Festival. The contemporary elements may well be as fun or meaningful as historical ones. But they inevitably lack the sense of exoticism, the effect of local cultural immersion, and the intellectuality of historical depth - qualities that centrally appeal to cultural tourists. For 
example, imagine how the Bun Festival's heritage tourism can be tarnished if suggestions like that offered by the Secretary for Home Affairs, Ho Chi-ping, were implemented. Ho proposed in 2005 to stage the Bun Scramble all year round and place dolls and cakes on the bun towers in order to turn it into a tourist attraction for all seasons and also a new kind of sport (Anon, 2005). If the introduction of contemporary elements to the Festival is left completely unchecked, the status of the Bun Festival as a historical heritage tourist occasion will become culturally unsustainable in the not very distant future.

Secondly, commercialization, the emphasis on spectacles, and sanitization tend to homogenized tourist products. The tourist products presently offered through Bun Festival tourism are limited and not very distinctive. They include the shopping for bun-themed souvenirs, the eating of vegetarian food and steamed buns, and spectatorship of spectacular performances (the Bun Scramble, floating children, lion dances, parades, Cantonese opera, and traditional acrobatics). The Festival has a potentially much larger repertoire of tourist products to offer. Examples include the watching of religious rituals, tours of historical sites and architecture, interaction with local hosts, and participation of festival activities instead of spectatorship. Instead of developing a variety of products, bureaucratic coordinators, commercial tour organizers, and public relations discourses of the Festival focus almost exclusively on originally marginal (but entertaining) aspects of the Festival for mass tourist consumption. Perhaps the majority of tourists are satisfied with such arrangements at present. But this is only the very beginning of global marketing of the Festival. As time goes on, tourists are likely to get tired of the limited variety of non-distinctive products. This applies to mass tourists who are not highly culturally knowledgeable as well as serious cultural tourists. The refusal to branch out from the most readily profitable, mass-appealing tourist products can therefore render Bun Festival tourism culturally unsustainable in the longer run.

Thirdly, because neoliberal tourism development places little policy weight on cultural heritage preservation and supplies minimal resources to it, the traditional know-how, technology, and historical knowledge that are required to reproduce the Festival year after year are in danger of dying out (Du Cros, 2007). It is reported that very few local residents are motivated to inherit the skill and technology of making floating children platforms and bun towers (Anon, 2006; Chan, 2008). Although a significant share of profits generated by Bun Festival tourism is channeled to local hands, they are captured mainly by the local business elite rather than the cultural producers who directly produce the cultural contents of the Festival. Of course the local business elite is informally forced by the local festival committee to contribute funds to ensure that the Festival take place yearly. However, they have no incentive to pay over the bare minimum of operating expenditures. The cultural work of making floating children platforms and of re-enacting other historical religious aspect of the Festival are supposed to be non-commercial, not-for-profit, and voluntary. But they are absolutely indispensable for the high profit parts of Bun Festival tourism - the selling of souvenirs, food, and tours. The Floating Children tradition of Yakou village in Guangdong province has been recognized as a provincial level intangible cultural heritage item by the Chinese government in 2008, for example (Ji, 2008). Similar recognition is not forthcoming in Hong Kong for Cheung Chau Island's Floating Children parade or Bun Scramble. If the government and businesses keep the lion share of benefits without even trickling them down to cultural producers, Bun Festival tourism could become culturally unsustainable as the cultural producers and their skills die out in the future.

Cultural sustainability is admittedly difficult to define and measure (Throsby, 2001). Unlike biological or ecological damage, there is not an objective way to determine how badly the cultural basis of a certain instance of heritage tourism has been undermined. Despite that, the cultural basis of heritage tourism is similar to the natural environment of tourism in an important aspect: they are being recklessly exploited as an externality for private profit and personal consumption. In the case of Bun Festival tourism, the unsustainable exploitation of culture is led by three major stakeholders. The government provides contextual support including reductionist global tourism PR discourses and neoliberal coordination of the Festival. Local and domestic businesses supplied homogenous and fast profit oriented products. And domestic tourists supply the economic demand through consuming the Festival in a mass touristic way. The only forces aligned against culturally unsustainable exploitation of the Festival are sophisticated international cultural tourists, critical intellectuals in Hong Kong, and older local residents of the Island. Yet with major stakeholders colluding with one another to push Bun Festival tourism towards a neoliberal direction, it is difficult to envision how the development of Bun Festival tourism could be transposed to a more culturally sustainable path in the near future.

\section{Conclusion}

The previous analyses show that problems that are common to heritage tourism development in developing localities are present in the case of Bun Festival tourism. They include the undermining of cultural authenticity, rampant commercialization and commodification, and local disempowerment. However, I have also mobilized arguments and documented evidence to show that a critique of Bun Festival tourism based on these problems is not neither adequate nor powerful. Some of the most controversial, cultural inauthentic innovations of the current form of the Festival are found to be historical legitimate and locally orchestrated revisions of tradition, or inevitable results of introducing personal safety or social justice in the Festival. Commercialization and commodification, though rampant, are found to 
have economically benefited local residents more than corporations from outside the Island. Local residents, generally embracing the neoliberal ideology of Hong Kong society, think the economic benefits they are gaining from the commercialized and commodified Bun Festival largely justify their negative consequences. Local residents also feel sufficiently empowered by economic profits even though they are political and social disempowered in moderate ways.

I suggest that a more convincing critique of the neoliberal orientation of Bun Festival tourism can be launched in term of cultural sustainability. The neoliberal development policies, management, and marketing discourses of the Bun Festival encouraged three serious problems: eclipsing of the heritage dimension of heritage tourism, homogenization of tourist products, and dying out of cultural producers, knowledge, and technologies that physically reproduce the Festival year after year. These are not merely abstract, intellectual problems of legitimacy and authenticity. Their impact is practical - they can greatly lower the profitability of Bun Festival tourism. More culturally sustainable policies and management are crucial for preventing Bun Festival tourism from going into the decline phase of its lifecycle as quickly as other over-exploited heritage tourist destinations do.

\section{References}

Anon. (2008a). Ping'anbao remai jingpin shouhuanying (Peace buns sell and souvenirs greatly welcomed). Hong Kong Daily News, May 13.

Anon. (2008b). Ping'anbao jingpin guanming Zhang Baochai (A peace bun-themed souvenir named after Cheung Bochai). Singtao Daily, May 11.

Anon. (2007a). Taiping Qingjiao ping'anbao 4 ri zhuan 10 wan (Selling Taiping Qingjiao peace buns and making a hundred thousand dollar in four days). Easyfinder, May 16.

Anon. (2007b). 'Ping'an' shiwu remai shengyi'e baiwan. ('Pingan' accessories sell well with a million dollars of revenue). Hong Kong Daily News, May 25.

Anon. (2006). Changzhou lao shifu tan houji wuren piaoshi tongnan tongnu nanzhou. (Old master of floating children performance in Cheung Chau laments the lack of a heir and difficulty of finding kids to perform). Takungpao, May 4.

Anon. (2005). Wenhua buyinggai bei geli baoshan qike qiangdangao (Culture should not be severed from the festival; bun towers should not be replaced by cake towers). May 10.

Broadcasting Unit of RTHK. (2007). Wutu Wuqing, Vol 3: Changjiao Changyou (My land and my love, volume 3: Jiao ritual lives on in Cheung Chau). Radio and Television Hong Kong. Aug 2.

Bryman, Alan. (2004). The Disneyization of Society. Sage Publishers.

Chan, Becky. (2008). You chang baoshan dao chang 'jiao' shan: luyou fazhan dui changzhou dajiao chuantong de yiyi yu defang chongquan (From bun scramble to plastic bun scramble: the meaning fof tourism development to Cheung Chau's tradition and local empowerment). Undergraduate Thesis, Hong Kong Baptist University.

Chiu, Yuen Mong and Tang, Ka Piu. (2005). Ping'anbao vs sugubao quwenhua de lüyou wenhua tuiguang zaidihua de linghuo kuaguo jingying (Peace buns versus vegetarian mushroom burgers: de-cultured cultural tourism marleting and localized, flexible cross-national management). Mingpao Daily, May 30.

Choi, Chi Chueng. (2007). Xisu bianbuting (Tradition is ever-evolving). Mingpao Daily, Jul 27.

(2002) Zuqun ningjü de qianghua: Cheung Chau Jiaohui. (Reinforcement of clan integration: Cheung Chau Island's Dajiao ritual). In Chan, Chen Hing (Ed.), Zhushen Jianianhua: Xianggang Zongjiao Yanjiu (Carnival of the gods: Studies of Hong Kong religions). Hong Kong: Oxford University Press.

Cole, S. (2007). Beyond authenticity and commodification. Annals of Tourism Research, 34(4), 943-960.

Du Cros, H. (2001). A new model to assist in planning for sustainable cultural heritage tourism. The International Journal of Tourism Research, 3(2), 165-170.

Editoral. (2005). Don't spoil festival with year-round bun scramble. South China Morning Post, May 14.

Fat, Chin Hon. (2008). Taiping qingjiao chanpin sharu shiqu qiangke (Taiping Qingjiao products into encroaching on the city's market). FACE Weekly, May 7.

Fung, Man Yee. (2007). Zhenjiabao zhi mi (The puzzle of real versus fake buns). Apple Daily, May 23.

Hampton, M. P. (2005). Heritage, local communities and economic development. Annals of Tourism Research, 32(3), 735-759.

Hao, Junyi. (2009). Xintui pingan qizibing ji xi nianqingke (New promotion of qizi biscuits to attract youthful customers). Wenweipo, Apr 12.

Harrison, David. (Ed.) (2001). Tourism and the Less Developed World: Issues and Case Studies. Oxon; New York: CABI Publishers. 
Hui, Polly. (2007). Plastic buns strip festival of heritage, says baker. South China Morning Post, Feb 15.

Hui, Sau Hing. (2006). Taiping qingjiao de zaiyanjiu (Re-investigating Taiping Qingjiao). InMedia Hong Kong. [Online] Available: http://www.inmediahk.net/public/article?item_id=117408\&group_id=122 (Jun 20, 2008).

Ji, Bei. (2008). Zhongshan guancha renwu diaocha jianshe wenhua mingcheng renwu zhuanfang xilie zhi er. (Zhongshan observation; people and investigation: interviews of figures who contributed to the construction of great cultural cities, interview 2) Nanfang Daily, Jun 26.

Kwan, Ying Yi. (2008). Qiangbao tuibian huanlai shangji yu... (Bun Scramble transformed into business opportunities and...). Mingpao Daily, May 8.

Lee, Siu Mei. (2007). Qiang 'jiaobao' tan wenhua chengchuan (A discussion of cultural inheritance from the perspective of 'plastic bun' scramble). Hong Kong Economic Journal, May 23.

Leung, Po Shan. (2007). Chuantong zaizao: 'Changzhou Taiping Qingjiao' yu 'Zhonghuan Miaohui' (Remaking tradition: Cheung Chau's Taiping Qingjiao and The Central's Temple fair).Cultural Studies@Lingnan 8(Nov) [Online] Available: http://www.ln.edu.hk/mcsln/8th_issue/feature_03.shtml (Jun 20, 2008).

$\mathrm{Ng}$, Chun Yan. (2008). Shengyi wangguo xinnian shanghu xiaohuo baiwan. (Better business than the Chinese New Years; businesses sold more than a million dollar worth of goods). Singtao Daily, May 13.

Oviedo-Garcia, M. Angeles, Mario Castellanos-Verdugo, and David Martin-Ruiz. (2008). Gaining residents' support for tourism and planning. International Journal of Tourism Research, 10(2), 95-109.

Ritchie, B. W. and Inkari M. (2006). Host community attitudes toward tourism and cultural tourism development: the case of the Lewes District, southern England. International Journal of Tourism Research, 8(1), 27-44.

Sofield, Trevor, H.B. and Sivan, A. (2003). From cultural festival to international sport: the Hong Kong Dragon Boat Races. Journal of Sport Tourism, 8(1), 9-12.

Throsby, David. (2007). Tourism, heritage and cultural sustainability: Three golden rules. In L. F. Girard and P. Nijkamp (Eds.), Cultural Heritage, Local Resources and Sustainable Tourism. Routledge. (2001). Economics and Culture. Cambridge: Cambridge University Press.

Wu, Kwok Wing. (2007). Zhengbao dananhai chenggong kao zou xiaxi (Bun bakery boy relying on business niche to gain success). Mingpao Daily, Jun 22.

Yeung, Yiu Tang and Chik, Wing Hang. (2008). Dafa ping'anbao cai shengyi jinsheng sancheng 4wan ren yongwang xiaofei Changzhou wangbao (Getting rich from peace buns; business went up 30 percent; 40 thousand people go visit Cheung Chau Island for consumption). Hong Kong Commercial Daily, May 13.

\section{Notes}

Note 1. I thank Becky Chan for discussing with me on a range of issues regarding the local residents of Cheung Chau Island and the Bun Festival.

Note 2. Floating children are also featured in a number of other Dajiao festivals in Taiwan and China. 